\title{
Long-term copper exposure promotes apoptosis and autophagy by inducing oxidative stress in pig testis
}

\author{
Yuanliang $\mathrm{Li}^{1}$ • Hanming Chen ${ }^{1}$ • Jianzhao Liao ${ }^{1} \cdot$ Keli Chen $^{1} \cdot$ Muhammad Tariq Javed $^{2} \cdot \mathrm{Na}$ Qiao $^{1} \cdot$ Qiwen Zeng $^{1}$. \\ Bingxian Liu ${ }^{1}$ - Jiangnan $\mathrm{Yi}^{1} \cdot$ Zhaoxin Tang ${ }^{1} \cdot \mathrm{Ying} \mathrm{Li}^{1,3}$
}

Received: 8 March 2021 / Accepted: 8 June 2021 / Published online: 15 June 2021

(C) The Author(s), under exclusive licence to Springer-Verlag GmbH Germany, part of Springer Nature 2021

\begin{abstract}
Copper $(\mathrm{Cu})$ is a heavy metal which is being used widely in the industry and agriculture. However, the overuse of $\mathrm{Cu}$ makes it a common environmental pollutant. In order to investigate the testicular toxicity of $\mathrm{Cu}$, the pigs were divided into three groups and were given $\mathrm{Cu}$ at 10 (control), 125, and $250 \mathrm{mg} / \mathrm{kg}$ body weight, respectively. The feeding period was 80 days. Serum hormone results showed that $\mathrm{Cu}$ exposure decreased the concentrations of follicular stimulating hormone (FSH) and luteinizing hormone (LH) and increased the concentration of thyroxine (T4). Meanwhile, $\mathrm{Cu}$ exposure upregulated the expression of $\mathrm{Cu}$ transporter mRNA (Slc31a1, ATP7A, and ATP7B) in the testis, leading to increase in testicular $\mathrm{Cu}$ and led to spermatogenesis disorder. The $\mathrm{Cu}$ exposure led to an increased expression of antioxidant-related mRNA (Gpx4, TRX, HO-1, SOD1, SOD2, SOD3, CAT), along with increase in the MDA concentration in the testis. In LG group, the ROS in the testis was significantly increased. Furthermore, the apoptotic-related mRNA (Caspase3, Caspase8, Caspase9, Bax, Cytc, Bak1, APAF1, p53) and protein (Active Caspase3) and the autophagy-related mRNA (Beclin1, ATG5, LC3, and LC3B) expression increased after Cu exposure. The mitochondrial membrane potential in the testicular tissue decreased, while the number of apoptotic cells increased, as a result of oxidative stress. Overall, our study indicated that the $\mathrm{Cu}$ exposure promotes testicular apoptosis and autophagy by mediating oxidative stress, which is considered as the key mechanism causing testicular degeneration as well as dysfunction.
\end{abstract}

Keywords Oxidative stress $\cdot$ Pig $\cdot$ Testis $\cdot$ Copper $\cdot$ Toxicity

\section{Introduction}

Copper $(\mathrm{Cu})$ is an important heavy metal being used in the industry and agriculture (Eheliyagoda et al. 2019). In animal production system, $\mathrm{Cu}$ is used as food additive that promote animal growth and also has an antimicrobial activity (Yang et al. 2017a, b; Villagómez-Estrada et al. 2020). However, the

Yuanliang Li and Hanming Chen have contributed equally to this work and shared as the co-first author.

Responsible Editor: Ludek Blaha

Ying Li

lying@scau.edu.cn

1 College of Veterinary, South China Agricultural University, Guangzhou 510642, China

2 Department of Pathology, Faculty of Veterinary Science, University of Agriculture, Faisalabad 38040, Pakistan

3 Key Laboratory of Animal Vaccine Development, Ministry of Agriculture and Rural Affairs, Guangzhou 510642, China excessive use of $\mathrm{Cu}$ is polluting the land and water sources Vázquez-Blanco et al. (2020). The animals can regulate the $\mathrm{Cu}$ homeostasis in vivo through $\mathrm{Cu}$ transporters (Petris et al. 2002; Kim et al. 2013). The recommended intake of $\mathrm{Cu}$ for adult animal is $2.00 \mathrm{mg} /$ day. Oral doses higher than 200.00 $\mathrm{mg} / \mathrm{kg}$ body weight (bw) can cause death (Li et al. 2020). The cytotoxicity of $\mathrm{Cu}$ is similar to iron and is associated with production of reactive oxygen species (ROS) leading to peroxidation of the membrane lipids, protein oxidation, and nucleic acid breakage (Tapiero et al. 2003).

To meet the meat consumption needs of the society, copper is widely used as a feed additive to enhance the production performance of the animals (He et al. 2016; Liu et al. 2018). Unlike classical antimicrobial growth promoters, $\mathrm{Cu}$ is inert and non-degradable in the environment, which poses challenges to the environmentalists (Jensen et al. 2016). The unreasonable addition of $\mathrm{Cu}$ in the feed causes environmental pollution, and long-term exposure to high $\mathrm{Cu}$ in the feed reverses the effect of promoting livestock growth into an inhibitory effect, even it has a toxic effect Li et al. (2010). 
The reproductive performance of livestock is important aspect of production (Schulze et al. 2020). The testis serves as the site of spermatogenesis but is vulnerable to oxidative damage due to the presence of large amount of highly unsaturated fatty acids and the presence of ROS Aitken and Roman (2008). Some studies indicated that the $\mathrm{Cu}$ could cause decrease in the antioxidant capacity and testicular spermatogenesis (Zhao et al. 2019; Zebral et al. 2019; Lin et al. 2020). Furthermore, $\mathrm{Cu}$ exposure upregulates the expression of genes of oxidative phosphorylation pathway (such as Cytc, SOD1, and GST) in the testis to induce ROS production, which is related with the toxicity of $\mathrm{Cu}$ in the testis (Zhao et al. 2019). These results reflect the disruption of balance between antioxidant and oxidant after $\mathrm{Cu}$ exposure, and it causes oxidative damage in the testis. The ROSs are one of the byproducts of normal mitochondrial metabolism and homeostasis, and the ROSs have biphasic effects, as the appropriate level of ROS has a physiological role in the cell differentiation and sperm capacitation, while excessive ROS can cause oxidative stress in the testis (Zorov et al. 2014). Excessive ROS can cause damage to the electron transport chain and then lead to mitochondrial dysfunction, which many studies have shown that oxidative stress may cause apoptosis through mitochondriadependent and mitochondria-independent pathways (Indo et al. 2007; Sinha et al. 2013). These findings have indicated a link between oxidative stress and apoptosis, and thus it contributes to the toxicity by $\mathrm{Cu}$. It has been found that $\mathrm{Cu}$ indeed is toxic to the organs by mediating oxidative stress and apoptotic pathways (Guo et al. 2017; Yang et al. 2017a, b; Yang et al. 2019a, b; Modanloo and Shokrzadeh 2019).

Previous studies found that long-term exposure to $\mathrm{Cu}$ leads to accumulation of $\mathrm{Cu}$ in the form of residues in the visceral organs, leading the upregulation of mitochondrial apoptotic pathway-related genes and the class $\mathrm{P} 13 \mathrm{~K}$ autophagy-related genes, which further promote damage in the tissues (Kheirandish et al. 2014; Chen et al. 2020; Shao et al. 2019). Autophagy is a process of cellular homeostasis, which plays an important role in the cell survival and maintenance through the degradation of cytoplasmic organelles, proteins, and macromolecules and is related with the recycling of breakdown products Levine and Kroemer (2019). Autophagy occurs mainly through the PI3K complex pathway. The nutrition, energy, and apoptotic states, all affects the progress of the autophagy. However, autophagy disorder may also promote cytopathy (Glick et al. 2010). Apoptosis, the programmed death of cells, is an essential component of various processes, including metabolism and disease development. The initiation of apoptosis mainly proceeds through the mitochondrial pathway by activation of the Akt, a serine/threonine kinase, extracellular signalregulated kinases (ERK1/2), p38, as well as c-Jun NH2-terminal kinase (JNK) pathway, and the endoplasmic reticulum stress pathway (Elmore 2007; Kerr et al. 1972). Although apoptosis and autophagy represent two distinct auto-degradation processes, there are also certain connections between them, reflected by the fact that molecularly the expression pathways of the two exist in many common genes (Zhao et al. 2015). To the best of our knowledge, there is no report indicating that $\mathrm{Cu}$ could induce testicular toxicity in vivo through oxidative stressinduced cell apoptosis and autophagy.

Although previous studies have evaluated the reproductive toxicity of $\mathrm{Cu}$, there is no study to verify that $\mathrm{Cu}$ poisoning mediates testicular apoptosis and autophagy disorder through oxidative stress mechanism. Thus, the purpose of this study was to investigate the mechanisms related with $\mathrm{Cu}$ exposure leading to testicular toxicity and the association between oxidative stress, apoptosis, and autophagy in this mechanism.

\section{Materials and methods}

\section{Animals and treatments}

Total of 12 pigs (30-day-old, procured from a pig farm in Shaoguan, Guangdong) were acclimatized for the experimental conditions before staring the treatment, and they were raised in the experimental animal center of South China Agricultural University during treatment. Before raising, pig houses were cleaned and disinfected with formaldehyde. All the feed and tools were disinfected and delivered to the pig houses after being irradiated by ultraviolet lamp in the transmission window. Pigs were wiped with povidone-iodine (1:200) for disinfection and then delivered to the pig houses after being irradiated by ultraviolet lamp in the transmission window. All pigs were fed twice a day, drinking freely, and a 12-h light/dark cycle was set. Experimental animal treatment was performed according to the guidelines of the Institutional Animal Care and Use Committee of South China Agricultural University (IACUC, SCAU).

\section{Experimental design}

In the study, 12 pigs were divided into three experimental groups; each group had four pigs. The $\mathrm{Cu}$ used was anhydrous copper sulfate $\left(\mathrm{CuSO}_{4}\right)$ as a $\mathrm{Cu}$ source. The dose of $\mathrm{Cu}$ was selected on the basis of a previous study by Yang et al. (2016). The control group pigs were fed on normal diet (with 10 $\mathrm{mg} / \mathrm{kg}$ bw $\mathrm{Cu}$ ) throughout the study and served as control group; the LG (low dose group) pigs were similar to the control group except additionally were fed with $125 \mathrm{mg} / \mathrm{kg}$ anhydrous copper sulfate (CuSO4); the $\mathrm{HG}$ (high-dose group) pigs were additionally fed with $250 \mathrm{mg} / \mathrm{kg} \mathrm{CuSO}$ to that of control group. After feeding pigs for 80 days, the pigs were properly restrained to collect the blood from the jugular vein, then sacrificed with sodium pentobarbital, and collected the testes (Oskam 1989). The left side of the testis was fixed in $4 \%$ paraformaldehyde solution, and the right side was cut off and digested with trypsin partly. The rest of the testicular 
tissue was frozen by liquid nitrogen and stored at $-80{ }^{\circ} \mathrm{C}$ in an ultra-low temperature refrigerator (Thomas Scientific, Swedesboro, NJ).

\section{Testicular coefficient evaluations}

All pigs were weighed before sacrifice, and both testicles were removed and weighed quickly after sacrifice. The testicular coefficient was calculated as:

Testicular coefficient $=\frac{\text { Testis weight }(\mathrm{KG})}{\text { Pig weight }(\mathrm{KG})} * 100 \%$.

\section{ICP-MS analysis testicular $\mathrm{Cu}^{2+}$ concentration}

The $20 \mathrm{mg}$ of testicular tissue was treated with $1 \mathrm{~mL}$ of aqua regia and $1 \mathrm{~mL}$ of hydrogen peroxide. All samples were transferred to the microwave-assisted digestion using MARSXpress (maximum power: $1200 \mathrm{~W}$ ) laboratory microwave digestion system (CEM, Matthews, NC, USA). After the samples were cooled, added deionized water, and diluted to $10 \mathrm{~mL}$, and the $0.22-\mu \mathrm{m}$ diameter filter (TJJinteng, China) was used to filter the solution. The amount of $\mathrm{Cu}^{2}+$ in the testis was measured by Agilent 1260/7700X ICP-MS (Agilent, USA). The concentration of heavy metal was calculated by 5-point calibration curve of ICP-MS, and the linearity of each target element was greater than 0.99 .

\section{Hormone analysis}

The serum estradiol (E2), testosterone (T), luteinizing hormone (LH), parathyroid hormone (PTH), thyroxine (T4), and follicle-stimulating hormone (FSH) were measured by using the Synergy HTX Multi-Mode Reader (BioTek, America) according to the manufacturer's protocol.

\section{Assessment of content of MDA and ROS in the testes}

Partial fresh testicular tissues were used to evaluate the oxidative stress-related indexes. According to the instructions provided by the manufacturer, using an ELISA kit (Beyotime Biotechnology Co., Ltd, Shanghai) to determine MDA level in the testes. About ROS, the instruction manuals provided by the manufacturer of the kit (Beyotime Biotechnology Co., Ltd., Shanghai) were followed. Fresh testicular tissue was made into cell suspension. The cell suspension was treated according to the guidance provided in the reactive oxygen species (ROS) assay kit (Beyotime Biotechnology Co., Ltd., Shanghai) and then used flow cytometry (Beckman Coulter Co., Ltd) to measure the ROS level in the tissue.

\section{Testicular pathology and apoptosis assessment}

After the pigs were sacrificed, the testicles and epididymis were removed, fixed in $4 \%$ paraformaldehyde solution (Shanghai EKEAR Biotech Co., Ltd, Shanghai) overnight, embedded in paraffin, sectioned at a thickness of $5 \mu \mathrm{m}$, and then stained with hematoxylin and eosin stain (H\&E) (Anhui Leagene Biotechnology Co., Ltd., Anhui). The stained sections were then analyzed by using a Leica DM1000 light microscope (Leica, German). As described in previous studies, to detect the apoptosis in the testis, paraffin sections of the testis were subjected to TUNEL assay staining (Beyotime Biotechnology Co., Ltd., Shanghai) using immunohistochemistry (Liu et al. 2018).

\section{Indirect immunofluorescence analysis}

To analyze the effects of $\mathrm{Cu}$ on the autophagy gene LC3B expression, indirect immunofluorescence staining of the testis sections was performed according to previously reported method (Chen et al. 2015). Briefly, the testicular sections were deparaffinized and processed through xylene (Guangzhou Chemical Reagent Factory, Guangzhou) and graded concentrations of ethanol (Guangzhou Chemical Reagent Factory, Guangzhou) and then followed the sodium citrate method to sequester the testicular tissue antigens; thereafter, treated with 0.5\% Triton X-100/1×PBS (Takara Biotechnology Co., Ltd., Anhui) and then blocked with 5\% skimmed milk, incubated with LC3B primary antibodies (Ruiying Biotech Co., Ltd., Jiangsu, China) for over $16 \mathrm{~h}$ at $4{ }^{\circ} \mathrm{C}$, and then incubated with FITC secondary antibodies (Beyotime Biotechnology Co., Ltd., Shanghai); and finally, used DAPI (Beyotime Biotechnology Co., Ltd., Shanghai) blocking reagent, and then by using Leica fluorescence microscope (Leica, German), the image was recorded.

\section{RT-PCR analysis}

The expression of mRNA for $\mathrm{Cu}$ transporter, oxidative stress, apoptosis, and autophagy-related genes in the testicular tissues were studied by RT-qPCR. Total RNA was harvested from testis samples with the TRIzol reagent (Takara Biotechnology Co., Ltd., Anhui) following the manufacturer's instructions. Synthesis of the first strand (cDNA) was performed with HiScript III RT SuperMix for qPCR (+gDNA wiper) (Vazyme Biotech Co., Ltd., Nanjing). Primers were designed with Primer 3.0 (http://bioinfo.ut.ee/primer3-0.4.0/) according to the gene sequence of the pig to produce an amplification product and tested on NCBI Primer-BLAST (https://www. ncbi.nlm.nih.gov/tools/primer-blast/). All the designed primer sequences were obtained (Sangon Biotech (Shanghai) Co., Ltd., Guangzhou). The primers used to amplify the genes are shown in Table 1. The GAPDH was used as a 
Table 1 Specific primers used for real-time PCR analyses

\begin{tabular}{|c|c|c|}
\hline Gene name & Forward primer $\left(3^{\prime}-5^{\prime}\right)$ & Reverse primer $\left(3^{\prime}-5^{\prime}\right)$ \\
\hline GAPDH & ACCCAGAAGACTGTGGATGG & AAGCAGGGATGATGTTCTGG \\
\hline SOD1 & CAGGGCACCATCTACTTCG & TCACCTTCAGCCAGTCCTTT \\
\hline SOD2 & GCTGGAAGCCATCAAACG & TTAGAACAAGCGGCAATCTG \\
\hline SOD3 & CTGACGCTGCTCTGTGCTTA & TCAACTCCTGCCAGATCTCC \\
\hline CAT & AGAGGAAACGCCTGTGTGAG & GTCCAGAAGAGCCTGAATGC \\
\hline Gpx4 & ATTCTCAGCCAAGGACATCG & TTTGACGTTGTAGCCAGCAG \\
\hline HO-1 & GCTGAGAATGCCGAGTTCAT & GGAAGTAGAGGGGCGTGTAG \\
\hline TRX & TTCCAATGTCGTGTTCCTTG & ACCCACCTTCTGTCCCTTTT \\
\hline Caspase3 & GCAGTTTTATTTGCGTGCTTC & TCCGTCTCAATCCCACAGTC \\
\hline p53 & CCTCACCATCATCACACTGG & CACAAACACGCACCTCAAAG \\
\hline Caspase8 & ACCTGGCTTCCCTCAAGTTC & TCCATCTCCTCCTCATTGGT \\
\hline Caspase9 & GACCTCCATCCTGTGGTGAT & GCATTTCCCTTGGCTCTGT \\
\hline Bax & AAGCGCATTGGAGATGAACT & GGCCTTGAGCACCAGTTTAC \\
\hline Cytc & AAGACTGGTCCAAACCTCCA & ACGCCATCAGTGTCTCCTCT \\
\hline APAF1 & TGGATGCAAAAGCTCGAAAT & TGCTCGTTGGCATTGAGTAG \\
\hline Bak1 & ATGACATCAACCGGCGATAC & TTGATGCCACTCTCGAACAG \\
\hline p62 & TCCAGCACAGAGGACAAGTG & ATGGGTCCAGTCATCGTCTC \\
\hline Beclin1 & GATAGTGGCGGAAAATCTCG & CATCTGGGCATAACGCATCT \\
\hline ATG5 & GCCATCAATCGGAAACTCAT & TGAAGCCACAGGACGAAAG \\
\hline LC3 & ССTTCTTCCTGCTGGTGAAC & GGGAGGCGTAGACCATGTAG \\
\hline LC3B & TGCAGCTCAATGCTAACCAA & CTTCATCCTTCTCGCTTTCG \\
\hline Slc31a1 & TGGCGGTGTTTTTACTAGCC & CTGCCCAACTGTTTTGTGTG \\
\hline ATP7a & AAGCTGTGGGCTTTCCAGTA & TCCTTTGTGGTGATCCTTCC \\
\hline ATP7b & TAGAAGGCAGGCTCAGGAAA & TCAATAGGTCCCAGGCTCAC \\
\hline ATOX1 & TCAACAAGCTGGGAGGAGTT & CAGGGTCTCCAGCAGAGTGT \\
\hline
\end{tabular}

housekeeping gene to normalize the target gene transcript lev$\mathrm{el}$, and the relative expression level of the selected gene was calculated by $2^{-\Delta \Delta \mathrm{ct}}$ method.

\section{Active Caspase 3 protein expression analysis}

Follow the previously described method, the quantitative immunoblotting was carried out (Chen et al. 2020). After homogenizing the testis samples, the protein concentration of each sample was measured by bicinchoninic acid (BCA) method (Beyotime Institute of Biotechnology, Shanghai, China). Proteins were separated on $12 \%$ SDS-PAGE gels and then transferred onto the polyvinylidene difluoride membranes (Millipore, USA). Incubations were performed using the Active Caspase3 (1:1000) primary antibody (Zen-bioscience Co., Ltd., Chengdu) for over $16 \mathrm{~h}$ at $4{ }^{\circ} \mathrm{C}$ with subsequent secondary antibody which was used at a dilution of 1:5000. Western blots were visualized using the commercial ECL solution (Millipore, USA). The signal was detected by X-ray film (TransGen Biotech Co., Beijing). Protein levels were then analyzed by ImageJ software. All the protein measurements were normalized to GAPDH, and data were expressed relative to the values in control group.

\section{Statistical analysis}

In the study, all the data are expressed as mean $\pm \mathrm{SD}$. The groups were compared by one-way ANOVA applying Tukey's test using IBM SPSS Statistics 25.0 Statistical Software (SPSS Inc., Chicago, IL, USA). Probability (P) values of $<0.05$ indicated that the difference is statistically significant. GraphPad prism 8.0 software (GraphPad Software Inc., San Diego, CA, USA) was used to visualize the data.

\section{Results \\ Effects of Cu toxicity on Cu transport carrier gene expression}

To verify that $\mathrm{Cu}$ exposure caused additional $\mathrm{Cu}$ transport into the pig testis, we determined the testicular $\mathrm{Cu}$ content and the levels of $\mathrm{Cu}$ transporter genes. In LG and HG groups, the levels of $\mathrm{Cu}$ transporter genes Slc31a1, ATP7a, ATP7b, and ATOX1 were significantly increased in a dose-dependent manner compared to the control group $(P<0.05)$ (Fig. 1A to $\mathrm{E})$. In parallel, the $\mathrm{LG}$ and $\mathrm{HG}$ groups showed increase in 

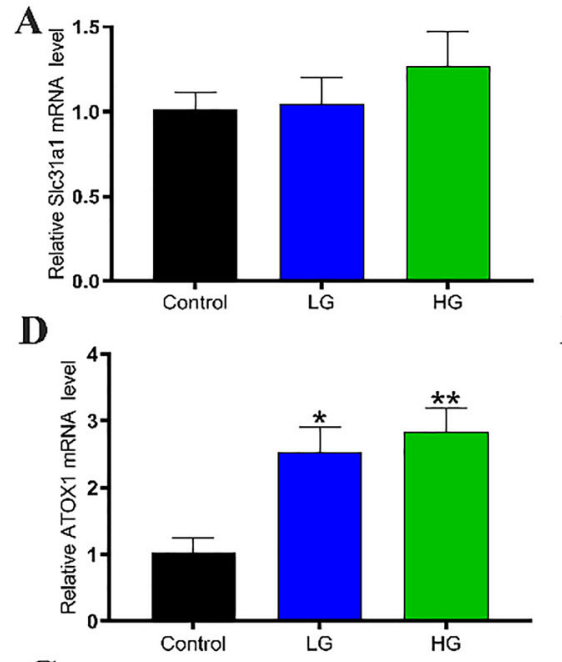

G
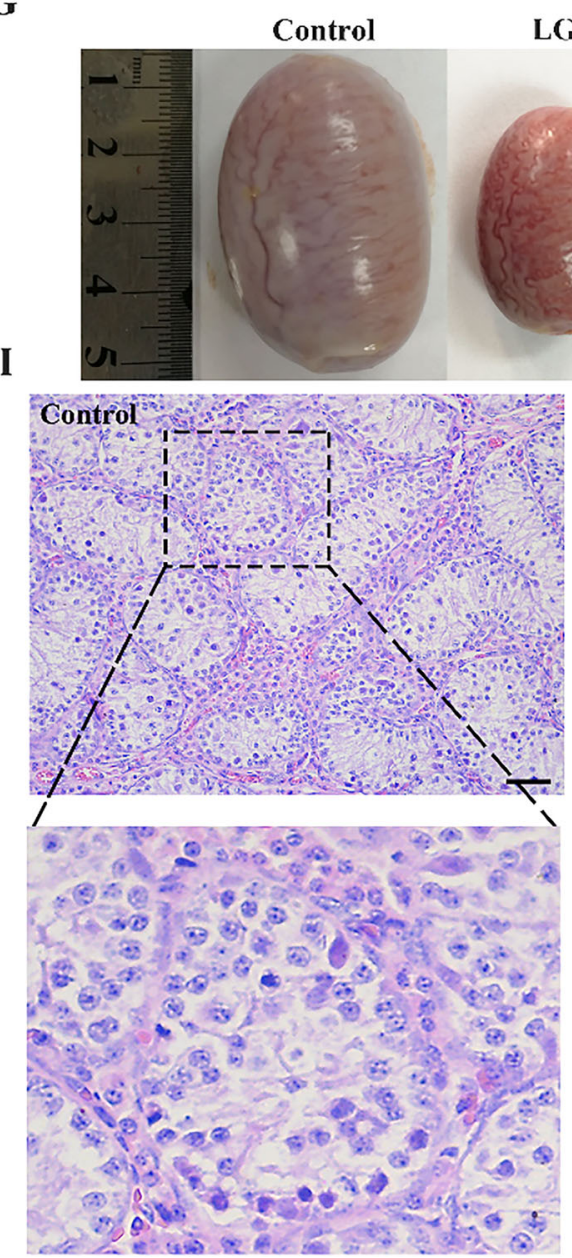

Fig. $1 \mathrm{Cu}$ enters the testes via copper transporter and causes pathological changes in the testes. A, B, C, and D The expression level of Slc31a1, ATP7a, ATP7b, and ATOX1 mRNA in the testes of the control, LG, and HG groups. E Testicular $\mathrm{Cu}$ content in the testes of the control, LG, and HG groups. F Testicular coefficient in the testes of the control, LG, and HG groups. G Testicular appearance in the testes of the control, LG, and

testicular $\mathrm{Cu}$ contents, with no significant difference compared to the control group $(P>0.05)$ (Fig. 1E).
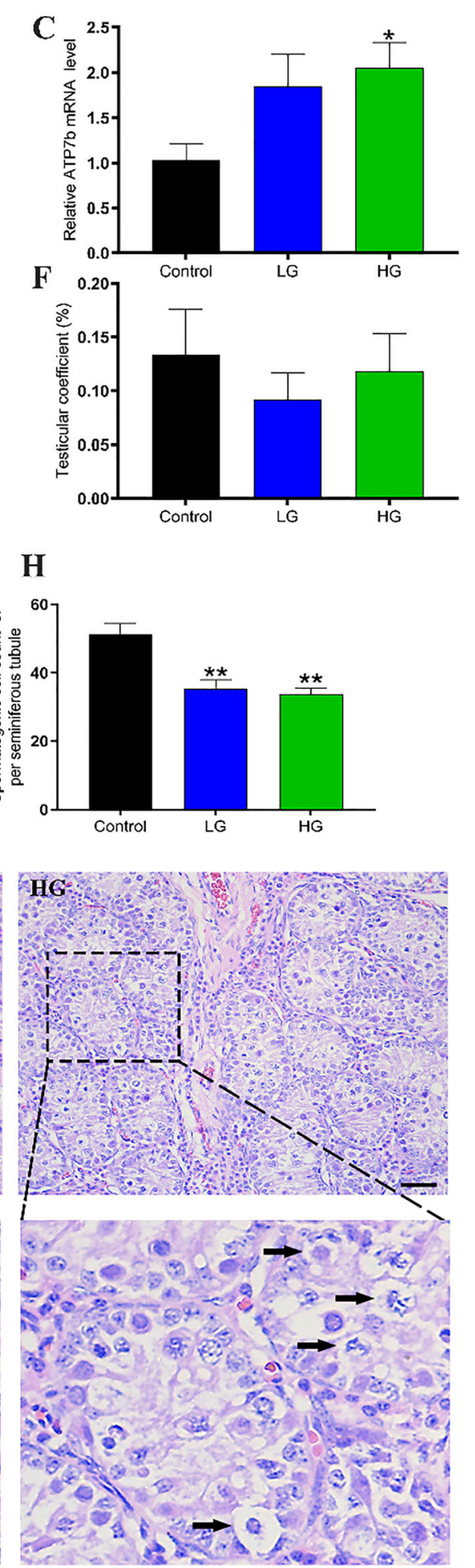

HG groups. H Spermatogenic cell count of per seminiferous tubule. I Histological cross sections of testicular samples. Representative H\&E staining images are shown. The copper-exposed boar testes show spermatocyte sloughing (arrow) and vacuolar degeneration in the seminiferous tubules (star). $* P<0.05, * * P<0.01$, $* * * P<0.001$

Then, to investigate the effects of $\mathrm{Cu}$ exposure on the morphology and function of testis, the testicular indices were 
calculated. We found that after $\mathrm{Cu}$ exposure, the testicular coefficient in LG and HG group appeared decreased; however, the difference was not significant $(P>0.05)$ (Fig. 1F). In morphological results, compared with the control group, the testicular volume of LG group was lower, while the testicular volume of HG group did not change significantly. However, compared with the control group, the testis of LG group and HG group showed expansion of blood vessel, i.e., congestion (Fig. 1G). Besides, $\mathrm{Cu}$ exposure resulted in a decrease in spermatogenic cells, as well as induced spermatogonia and spermatocytes sloughing (arrow) and vacuolar degeneration (star) in the seminiferous tubules (Fig. $1 \mathrm{H}$ and I). Moreover, $\mathrm{Cu}$ exposure changed the serum hormone levels in pigs. Among them, the levels of E2, T4, and T in the LG and HG group were increased, while the levels of LH and FSH in LG and HG group were decreased, compare with control group, but the PTH showed no change after $\mathrm{Cu}$ exposure. The change in $\mathrm{LH}$, T4, and FSH were significant $(P<0.05)$ (Table 2$)$. All the results suggested that the $\mathrm{Cu}$ exposure does affect the testis through change in the levels of serum hormones and the expressions of $\mathrm{Cu}$ transport carrier genes, as well as caused damage to testicular tissue.

\section{$\mathrm{Cu}$ exposure induce testicular oxidative stress}

Spermatogenesis is a process of rapid cell division, which means a high rate of oxygen consumption. Maintaining testicular homeostasis and avoiding oxidative stress can ensure normal spermatogenesis. The results of the study suggest that $\mathrm{Cu}$ exposure led to a high concentration of $\mathrm{Cu}$ in testes, and the spermatogenesis was reduced, and the testicular tissue showed degenerative changes. Therefore, to investigate the role of oxidative stress in testicular toxicity of $\mathrm{Cu}$, we determined whether the testicular oxidation and antioxidant balance could be affected after $\mathrm{Cu}$ exposure. Frist, RT-PCR was used to determine the relative mRNA expression levels of antioxidant factors in the testis. Results showed that, the relative mRNA expression levels of Gpx4, TRX, HO-1, SOD1, SOD2, SOD3, and CAT increased after $\mathrm{Cu}$ treatment. Compared with the control group, the change of the relative
mRNA expression levels of antioxidant factors in LG and HG groups were significantly different $(P<0.05)$ (Fig. 2A). Then, we used flow cytometry to determine the testicular ROS level, and we found that the level of ROS in the testes increased after $\mathrm{Cu}$ treatment. The increase of ROS in LG group was significantly different $(P<0.05)$, but in the HG group was not $(P>$ 0.05 ) (Fig. 2B and C). Furthermore, we found that the content of MDA in the testes increased in the LG and HG groups, but the difference between control group and treatment groups were not significant $(P>0.05)$. These results suggest that $\mathrm{Cu}$ exposure disrupts the balance of oxidants and antioxidants in the testes, resulting the oxidative stress in testes.

\section{Oxidative stress that $\mathrm{Cu}$ mediated promotes apoptosis and autophagy in the testes}

Considering that oxidative stress will induce oxidative damage to DNA, protein, and lipids. Therefore, we evaluated the apoptosis in the testis. Results showed that, all the apoptosisrelated factors that we measured were increased in a dosedependent manner. In short, the relative mRNA expression levels of Caspase3, Caspase8, Caspase9, APAF1, p53, Bax, Bak1, and Cytc increased after $\mathrm{Cu}$ exposure. Meanwhile, compared with control group, the expressions of Caspase8, Caspase9, and Cytc in LG group and the expression of Caspase3, Caspase8, Caspase9, APAF1, p53, Bax, Bak1, and Cytc in $\mathrm{HG}$ group were significantly different $(P<0.05)$ (Fig. 3A). Next, we found that $\mathrm{Cu}$ exposure caused increased expression of Active Caspase 3 protein in a dose-dependent manner, and the difference between control and HG groups were significant $(P<0.05)$ (Fig. 3B and $\mathrm{C}$ ). Moreover, we measured the mitochondrial membrane potential of testes by using JC-1 fluorescent probe, and the results showed that, the testicular JC-1 aggregates decreased in a dose-dependent manner. Compared with the control group, JC-1 aggregates in LG and HG groups decreased significantly $(P<0.05)$, indicated that the testicular mitochondrial membrane potential decreased after $\mathrm{Cu}$ exposure (Fig. 3D and E). Furthermore, the TUNEL staining was used to detect apoptosis in testicular tissue, and we found that compared with the control group,
Table 2 Effects of dietary copper exposure on serum hormone levels in pigs.

\begin{tabular}{llll}
\hline Measurement & Control & LG & HG \\
\hline Estradiol (pmol/L) & $88.62 \pm 4.49^{\mathrm{a}}$ & $96.43 \pm 5.16^{\mathrm{a}}$ & $98.12 \pm 3.77^{\mathrm{a}}$ \\
Testosterone (nmol/L) & $88.74 \pm 0.74^{\mathrm{a}}$ & $85.02 \pm 1.83^{\mathrm{a}}$ & $100.81 \pm 8.93^{\mathrm{a}}$ \\
Luteinizing hormone (ng/L) & $7.20 \pm 1.13^{\mathrm{a}}$ & $2.63 \pm 0.23^{\mathrm{b}}$ & $2.84 \pm 0.32^{\mathrm{b}}$ \\
Parathyroid hormone (pg/mL) & $323.32 \pm 9.01^{\mathrm{a}}$ & $330.23 \pm 9.17^{\mathrm{a}}$ & $321.59 \pm 4.00^{\mathrm{a}}$ \\
Thyroxine (pmol/L) & $514.27 \pm 35.68^{\mathrm{a}}$ & $540.00 \pm 9.18^{\mathrm{ab}}$ & $618.58 \pm 38.50^{\mathrm{b}}$ \\
Follicle-stimulating hormone (U/L) & $3.55 \pm 0.33^{\mathrm{a}}$ & $2.57 \pm 0.27^{\mathrm{b}}$ & $2.80 \pm 0.16^{\mathrm{ab}}$ \\
\hline
\end{tabular}

Data are the mean with S.E. $(n=4)$. Within rows, values with different superscript letters differ significantly $(P<$ 0.05 , one-way ANOVA) 
Fig. $2 \mathrm{Cu}$ exposure induced oxidative stress. A The relative expression levels of antioxidants mRNA in the testes of the control, LG, and HG groups. B The levels of ROS in the testes of the control, LG, and HG groups. C Relative fluorescence intensity of DCF of the control, LG, and HG groups. D Testicular MDA content in the control, LG, and HG groups. $* P<$ $0.05, * * P<0.01, * * * P<0.001$

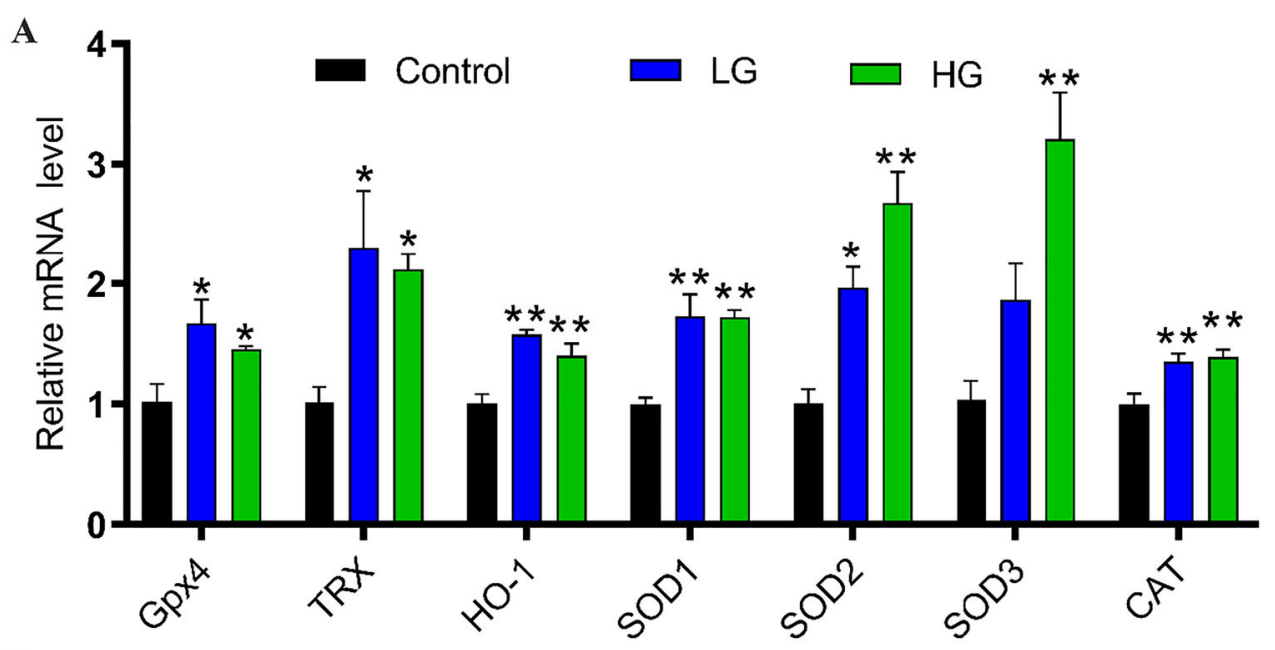

B

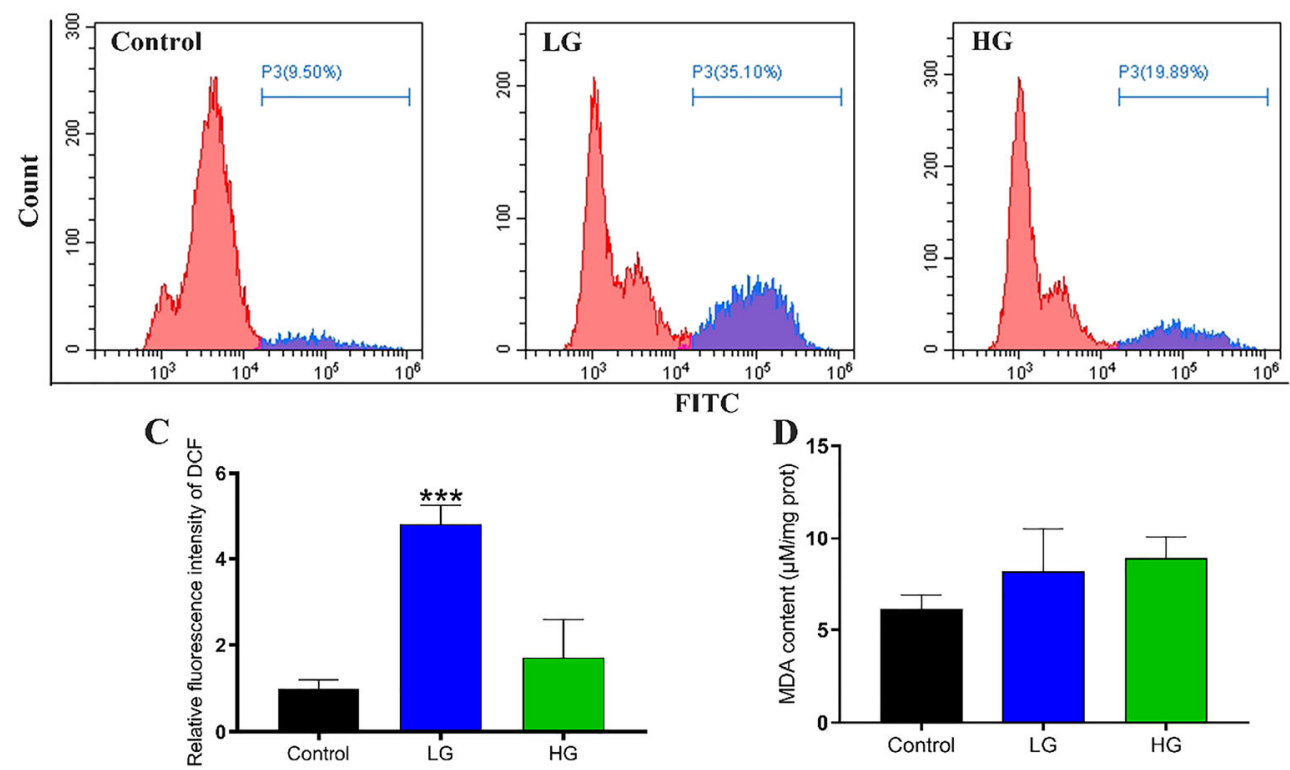

the number of TUNEL-positive spermatocytes (arrow) in the testes in LG and $\mathrm{HG}$ groups increased. All the results showed that oxidative stress caused decrease in mitochondrial function, promoted the apoptosis in testis, and induced the spermatogenesis disorder by damaging sperm DNA.

Autophagy is not only playing a role in homeostasis of cellular nutrients but also is involved in cell death. Considering that decreased mitochondrial function triggers cellular autophagy, leading to the degradation of mitochondria by autophagosomes. The expressions of autophagy-related factors were determined. The results showed that, the relative mRNA expressions of autophagy-related factors like Beclin1, p62, ATG5, LC3, and LC3B were increased after $\mathrm{Cu}$ exposure, and compared with control group, the expressions of ATG5 and LC3B in LG group were significantly increased $(P<0.05)$, while in HG group, the expressions of LC3, ATG5, LC3B, and Beclin1 were significantly increased $(P<$ 0.05 ) (Fig. 4A). In addition, the LC3B-positive cells in testes increased after $\mathrm{Cu}$ exposure, and the LC3B mean optical density in LG and HG groups was significantly increased compared with the control group $(P<0.05)$ (Fig. 4B and C). All the results suggested that the testicular oxidative stress promotes autophagy in testis via Beclin1/ATG5/LC3 autophagy signals.

\section{Discussion}

The $\mathrm{Cu}$ is widely used in industrial and agricultural production system, but the long-term application of copper causes environmental pollution. The environmental pollution can lead to chronic exposure of copper in animals by ingesting water and plants with high copper contents. One of the effects can be on the testis in animals which is a potential danger. As previous studies have reported, copper can accumulate in the testes via CRT1 and can cause toxic damage to the testes (Ghaffari et al. 
A
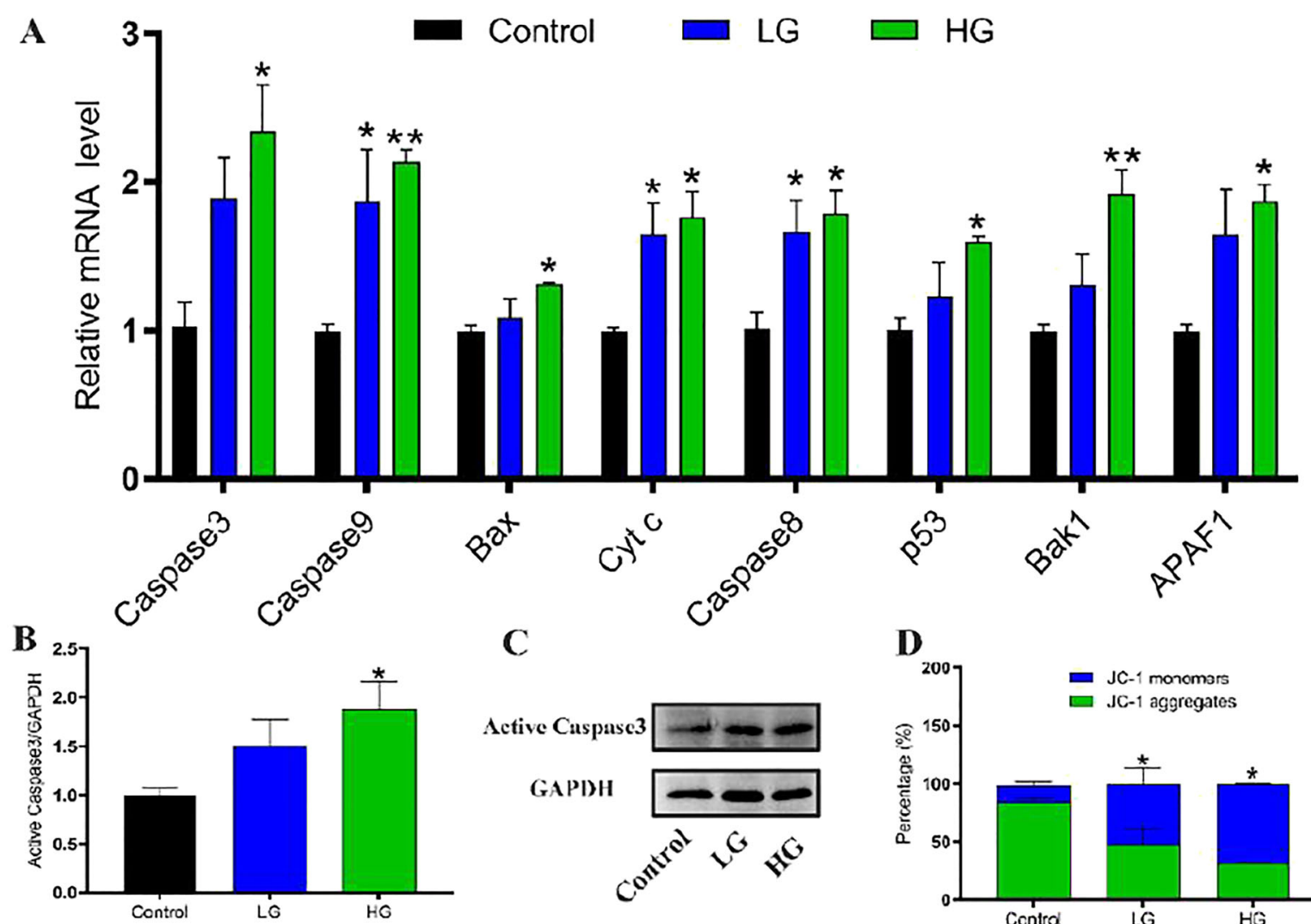

C

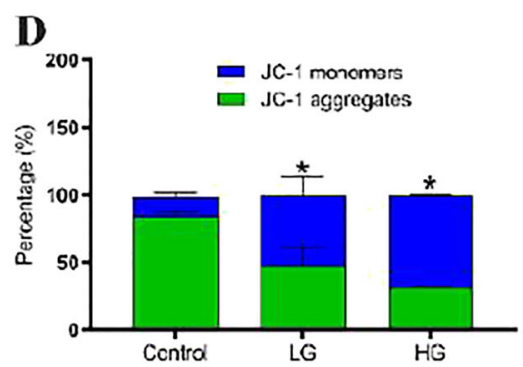

E
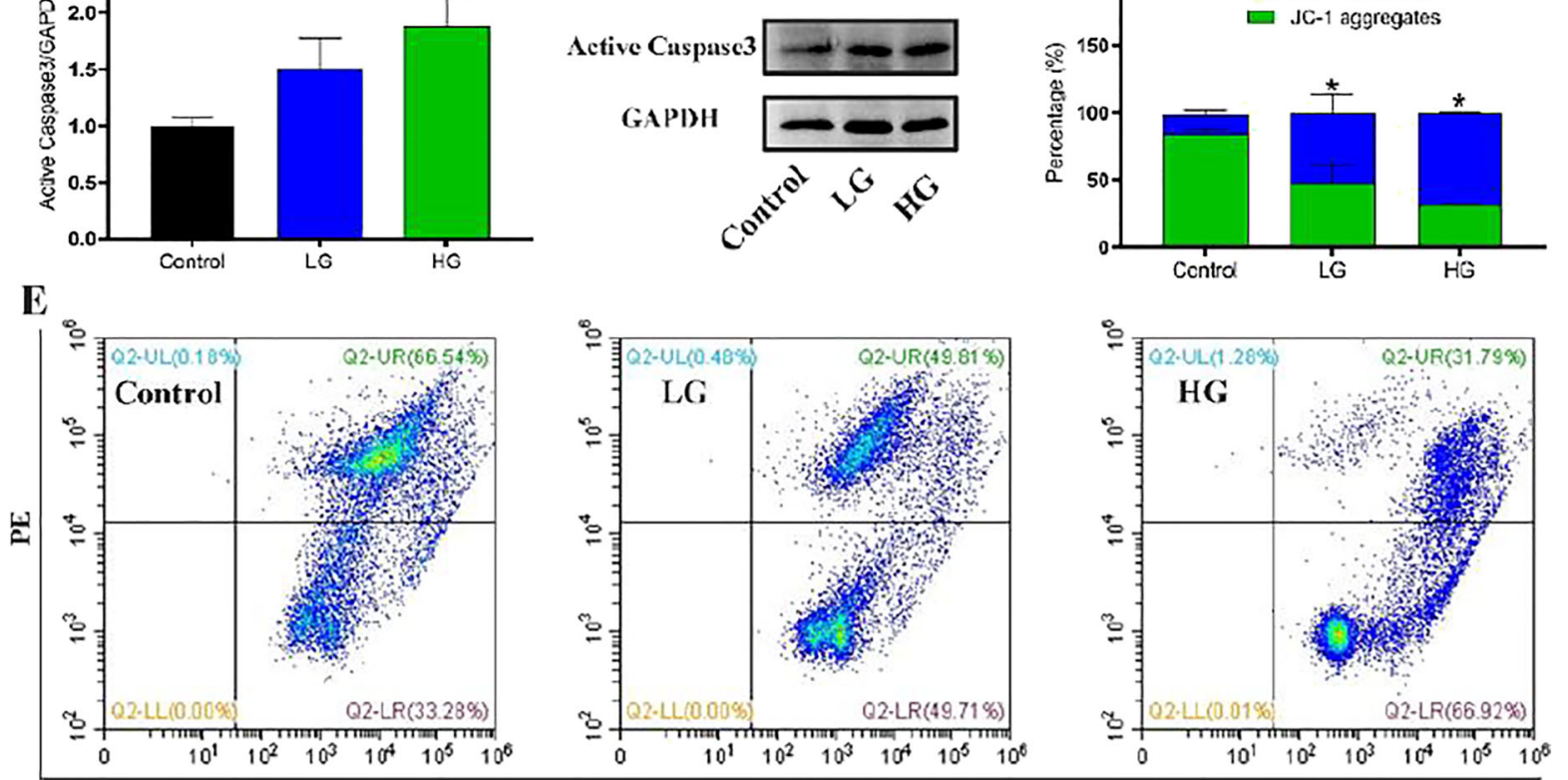

F
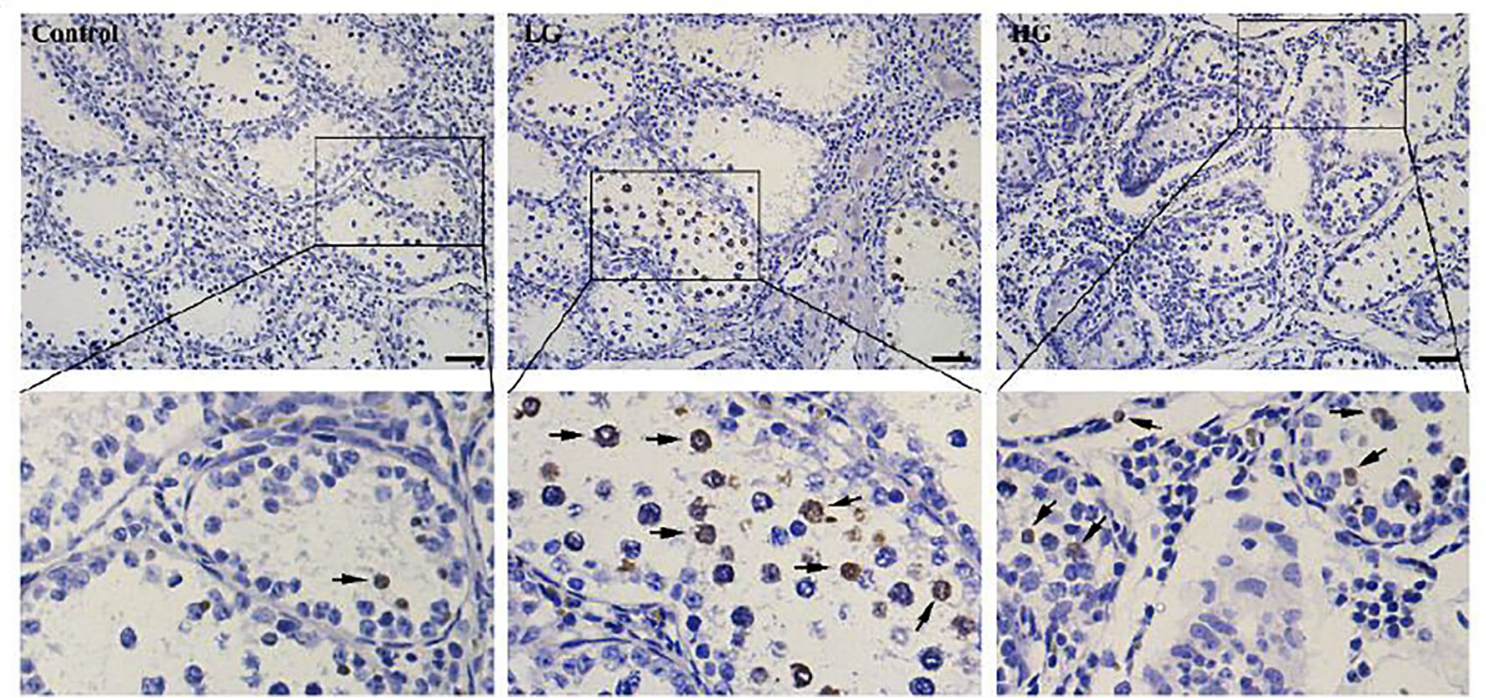
4 Fig. $3 \mathrm{Cu}$ treatment induced increased apoptosis through mitochondrial apoptosis pathway in the testis. A The expression levels of apoptoticrelated mRNA in testes of the control, LG, and HG groups. $\mathbf{B}$ and $\mathbf{C}$ The relative expression levels of Active Caspase 3 protein in testes of the control, LG, and HG groups. D The percentage of JC-1 monomers and JC-1 aggregates in the testes of the control group, LG group, and HG group. E Expression of results of both green and red JC-1 fluorescence intensities in control group, LG group, and HG group. F TUNEL staining was performed on testicular sections of the three groups. The apoptosis of spermatocytes by $\mathrm{Cu}$ inducing was observed under microscope (arrow)

2019; Lee et al. 2001). Some researchers have found that the copper causes testicular toxicity, through oxidative stress and thus leads to disorders of spermatogenesis (Kheirandish et al. 2014; Chen et al. 2020). However, due to the complexity of the testicular internal environment and function, the potential mechanisms of copper-induced testicular toxicology remained obscured.

In this study, we firstly observed the effect of $\mathrm{Cu}$ exposure on the testes and verified the $\mathrm{Cu}$ accumulation in the testis by determining the testicular $\mathrm{Cu}$ contents and testicular $\mathrm{Cu}$ transporter-related gene expression. The results showed that $\mathrm{Cu}$ accumulate in testis through upregulation of $\mathrm{Cu}$ transporters Slc31a1 (CTR1) ATP7a, ATP7b, and ATOX1. The $\mathrm{Cu}$ ion entry into cells is mediated by $\mathrm{Cu}$ transporters (CTR), and $80 \%$ of $\mathrm{Cu}$ ion is transported into the cell by CTR1, which is encoded by Slc31a1 gene (Ogórek et al. 2017). The intracellular $\mathrm{Cu}$ ions are supplied to SOD1 and metallothionein (MT), and excessive $\mathrm{Cu}$ ions will bind to the ATOX1 protein and then be transported to ATP7A and ATP7B, which can transport $\mathrm{Cu}$ ions to outside the cell or into the blood, respectively (Herman et al. 2020). The upregulated expression of the testicular copper transporter gene indicated that the concentrations of $\mathrm{Cu}$ in the testicular cells was beyond the range of tolerance in testicular cells; for that, $\mathrm{Cu}$ transporter gene expression was elevated in order to maintain testicular cell homeostasis. Moreover, in this study, the rising $\mathrm{Cu}$ content of testis in LG and HG groups also proved the above perspective. Interestingly, we observed that the testicular $\mathrm{Cu}$ content was higher in the LG group than in the HG group, which may be related to the elevated expression of ATP7A and ATP7B in the testes, and similar results have been reported in other studies ( $\mathrm{Li}$ et al. 2021). Then, $\mathrm{Cu}$ exposure caused the decrease in testicular coefficient, testicular degeneration, and sloughing of spermatocytes in the testicular tissue, and these results were similar to previous reports (Zhang et al. 2016; Chen et al. 2020). Therefore, we speculate that the $\mathrm{Cu}$ exposure caused testicular toxicology probably because the high concentrations of $\mathrm{Cu}$ caused upregulated expression of testicular $\mathrm{Cu}$ transporters, resulting in $\mathrm{Cu}$ to accumulate in the testicular tissue, which damages the testis.

Besides, the hormones play an important role in spermatogenesis and testicular growth; serum hormones can also represent whether testicular function is normal (Grande et al.
2019). The results that we found showed that the levels of FSH and LH decreased significantly; conversely, the serum E2 and TH levels increased, though the results of E2 were not significant. Interestingly, serum T and PTH levels did not change in response to treatment with different concentrations of $\mathrm{Cu}$. In other studies, serum $\mathrm{T}$ levels were significantly reduced by $\mathrm{Cu}$ treatment; however, it has also been found that $\mathrm{Cu}$ exposure does not affect serum T levels (Zhang et al. 2016; Chen et al. 2020). The LH and FSH can respectively induce proliferation of testicular Leydig cell and Sertoli cell, and LH additionally supports a normal increase in the testicular size (Wells et al. 2013). The TH is important for growth, development, and metabolism, and testicular development is also highly dependent on TH status (Hernandez 2018). The E2 is expressed in male testes and regulates the survival and apoptosis of germ cells, and excessive or insufficient estrogen levels can affect the testicular function (Correia et al. 2015; Sierens et al. 2005). Combined with all the results, we found that the changes in TH, E2, FSH, and LH levels affected the growth and function of the testicular tissue of the pig after $\mathrm{Cu}$ exposure.

As important antioxidants in cell, SOD, HO-1, CAT, Gpx4, and TRX function to eliminate the oxidation products and antioxidants (Liu et al. 2021b; Zhang et al. 2020; Wang et al. 2021). The MDA content reflects the severity of body exposure to free radicals, and ROS as a common oxidation product in cells, excessive ROS cause oxidative stress Yang et al. (2019a, b). After $\mathrm{Cu}$ exposure, to avoid the oxidations induced oxidative damage to the testes, the expression of antioxidants increased. Therefore, we observed that the expressions of antioxidant-related genes (SOD1, SOD2, SOD3, HO1, CAT, Gpx4, and TRX) were increased in the testes, as well as the ROS and MDA levels. The $\mathrm{Cu}$ exposure is known to cause a decrease in activity of antioxidants (Wan et al. 2020). In order to avoid the adverse effects of excessive oxidants, the overexpression of antioxidants is to resist the oxidant's activity. Interestingly, with the increase of $\mathrm{Cu}$ dose, the level of ROS in the testes decreased; we speculate that the increased expression of antioxidants enhances the antioxidant capacity of the testis and enables the testis to clear excessive ROS. Nevertheless, the content of MDA in the testes did not decrease, and increased continuously, which reflected that the testes were still in the imbalance state that oxidation capacity was higher than the antioxidant capacity, which means the overexpression of antioxidants still does not decrease the oxidant production. Altogether, results suggested that the oxidation and antioxidant balance dysregulation may be a key mechanism in $\mathrm{Cu}$-induced testicular toxicity (Liao et al. 2019).

Next, we further observed that the $\mathrm{Cu}$ exposure promoted apoptosis and autophagy in the testes, and it was associated with oxidative stress. The $\mathrm{Cu}$ exposure upregulated apoptotic signals. Apoptosis is characterized by caspase activation, 


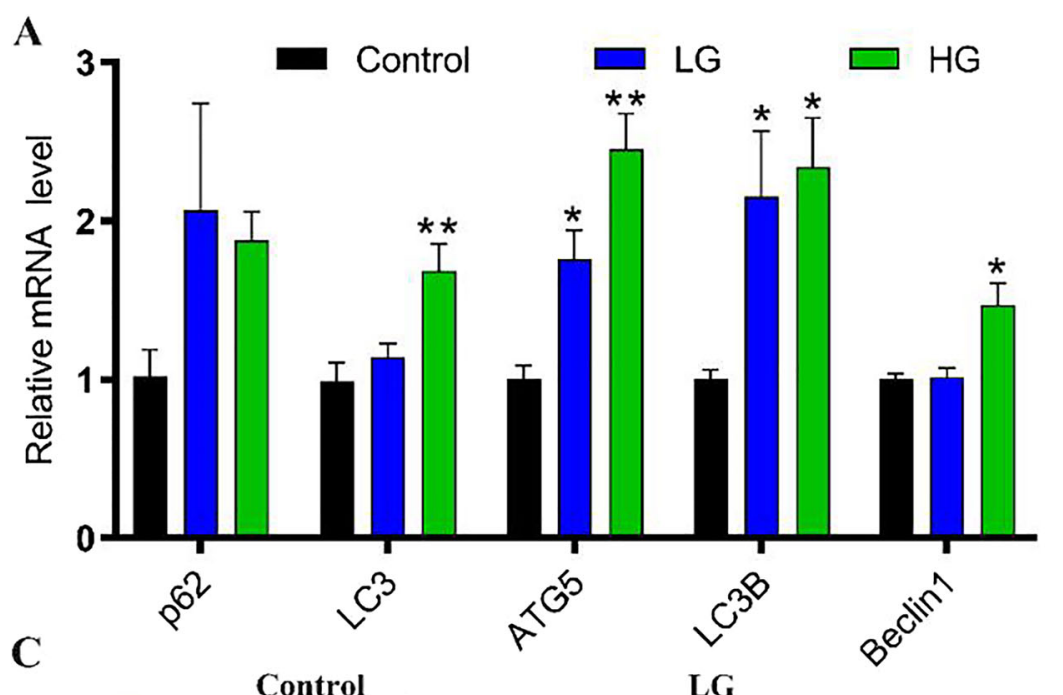

B
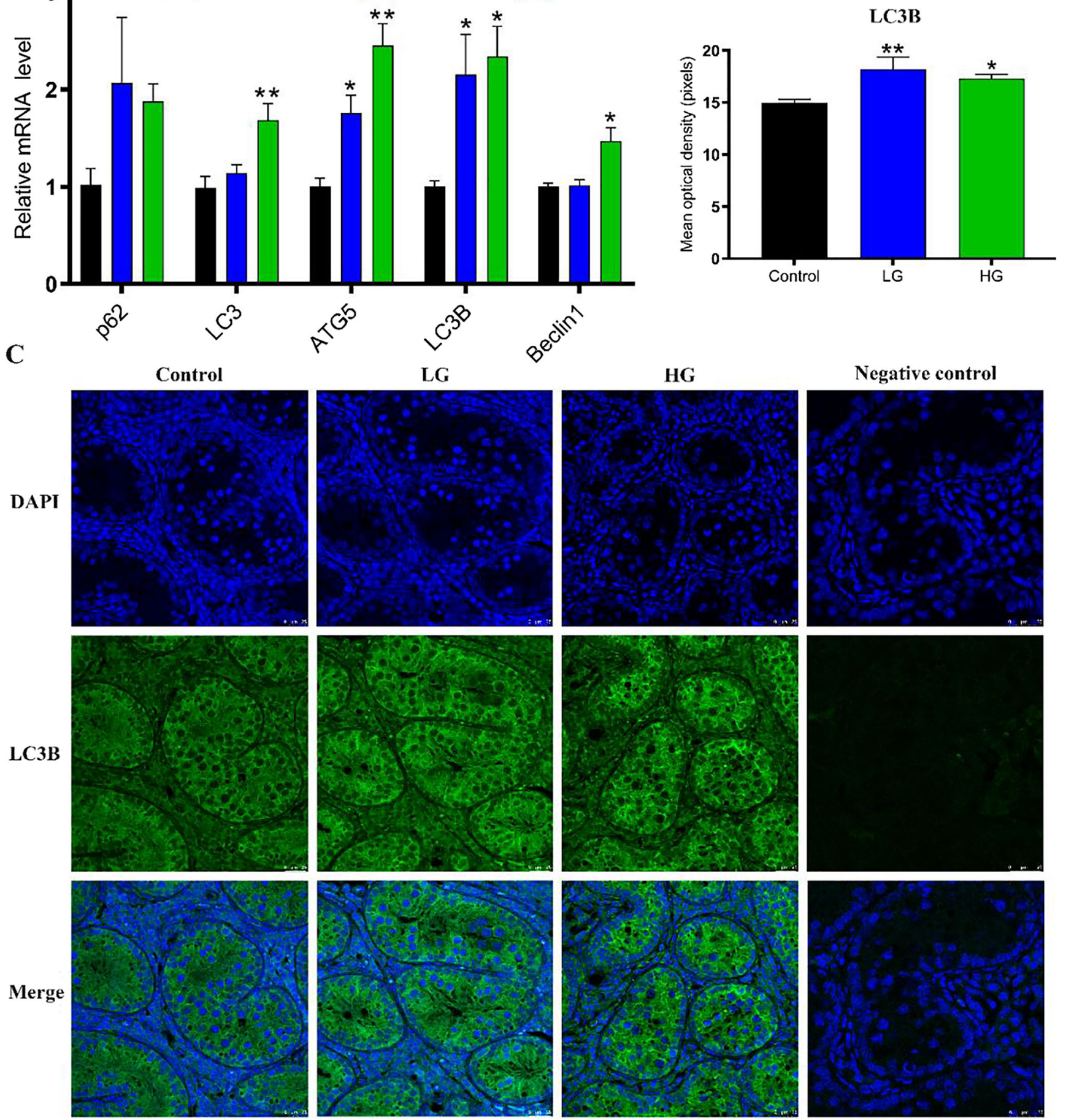

Fig. 4 The increase of autophagy induction by $\mathrm{Cu}$ in the testes. $\mathbf{A}$ The relative expression levels of autophagy-related mRNA in the testes after treated pigs with $9 \mathrm{mg} / \mathrm{kg}$ bw, $125 \mathrm{mg} / \mathrm{kg}$ bw, and $250 \mathrm{mg} / \mathrm{kg}$ bw Cu. B The LC3B mean optical density in the testes after treated pigs with 9

$\mathrm{mg} / \mathrm{kg}$ bw, $125 \mathrm{mg} / \mathrm{kg}$ bw, and $250 \mathrm{mg} / \mathrm{kg}$ bw Cu. C Expression and location of LC3B was detected by immunofluorescence staining for evaluate the testes autophagy. $* P<0.05, * * P<0.01$, *** $P<0.001$

which is playing a central role in it; each of the apoptotic pathways activates the apoptosis initiator caspase via specific triggering signals, which ultimately activates the apoptosis executioner Caspase3 (Elmore 2007). Mitochondria are important organelles for oxidative phosphorylation as well as ATP production and consumption in eukaryotic cells Yang et al. (2019a, b). The impairment of mitochondria can induce an increase in oxidative products, which in turn can 
further damage the cell, and induce apoptosis Sun et al. (2020). In this study, at first, the ROS upregulated the expression of Caspase 8 by suppressing anti-inflammatory-related signals of the extrinsic pathway, and ROS further promoted the expression of Bak1, Bax, and Cytc signaling, which regulate the mitochondrial apoptotic pathway (Sinha et al. 2013; Tummers and Green 2017). Meanwhile, p53 also promotes the expressions of Bax and Bak1 in mitochondrial apoptotic pathway by interacting with Bcl-2 family of proteins (Estaquier et al. 2012; Wang et al. 2021). And then Cytc binds to the apoptotic factor APAF1, activates Caspase9, and finally promotes Caspase 3 expression with Caspase8 signaling, eventually inducing apoptosis (Sinha et al. 2013; Tummers and Green 2017; Liu et al. 2021a). The decrease in proportion of JC-1 aggregates indicated decreased mitochondrial membrane potential in the testis, which is a sign of the early stage of apoptosis (Savitskiy et al. 2003). Terminal deoxynucleotidyl transferase-mediated dUTP nick end labeling (TUNEL) assay was used to detect DNA fragmentation by labeling the free 3'- hydroxy terminal. In short, TUNEL is a method of staining cells by labeling broken DNA, which is often used to determine cells in the early stage of apoptosis Mirzayans and Murray (2020). To further demonstrate the association among oxidative stress, mitochondria, and apoptosis, we also measured the mitochondrial membrane potential and TUNEL-positive cells in testes. Not unexpectedly, $\mathrm{Cu}$ exposure caused decrease in mitochondrial membrane potential and increase in TUNEL-positive cells in the testes. Spermatogenesis is a process of vigorous cell division, which causes a lot of oxygen consumption. When testicular antioxidant level is decreased, spermatocytes are vulnerable to oxidative damage, and thus our results were similar as that most TUNEL-positive cells in this study were spermatocyte (Kang et al. 2021).

Overall, $\mathrm{Cu}$-mediated oxidative stress is associated with testicular apoptosis. The oxidative stress promotes testicular apoptosis by reducing mitochondrial function, regulating molecules of apoptosis pathway, and damaging the DNA.

Oxidative stress affects chromatin structure and consequently mediates many cellular changes, including regulation of gene expression, cell death, survival, and mutagenesis, and the oxidative stress can crosstalk with autophagy machinery (Kreuz and Fischle 2016; Filomeni et al. 2015). This study determined the expression of autophagy-related genes in the testes and found a significant increase in expression of autophagy-related genes like ATG5, LC3, LC3B, and Beclin1 after $\mathrm{Cu}$ exposure. Then we performed LC3B localization and semi-quantitative analysis of pig testis sections by using immunofluorescence staining and observed that LC3B mean optical density was enhanced in the pig testicular seminiferous tubules. Previous reports have suggested that oxidative stress induces increase in levels of LC3B, and overexpression of $\mathrm{LC} 3 \mathrm{~B}$ would promote the formation of autophagosome, which is consistent with our results
(Satyavarapu et al. 2018). The p62 is an autophagy receptor protein that mediates the selective autophagy of ubiquitinated cargos, and if autophagy is promoted through this pathway, p62 will be largely recruited and then downregulated SánchezMartín et al. (2019). We have not found that the expression of p62 has changed significantly after $\mathrm{Cu}$ exposure, suggesting that $\mathrm{Cu}$ does not promote autophagy by regulating p62. The Beclin1, as one of the components of PI3K complex, is responsible for initiating the formation of autophagy, and oxidative stress can promote the expression of Beclin1 (Shi et al. 2019). The upregulation of Beclin1 positively regulates the autophagy by promoting PI3K complex synthesis (Van Erp et al. 2017). Once autophagy is started, autophagosome membrane elongation is regulated by LC3 and ATG5 (Van Erp et al. 2017). Altogether, our findings indicated that the oxidative stress mediated by $\mathrm{Cu}$ promotes autophagy in testes by regulating Beclin1/ATG5/LC3 signaling.

Still, due to the limited antibodies from pigs, we only measured the expression of oxidative stress, apoptosis, and autophagy-related genes at the gene level. To address this deficiency, we continue to investigate the testicular toxicity mechanism of $\mathrm{Cu}$ based on the results of this study in the future. In addition to investigate whether $\mathrm{Cu}$ exposure can promote the expression of gene-related proteins that we have detected in this study, the gene expression of upstream-related pathways of apoptosis and autophagy should be further explored.

\section{Conclusions}

In this study, we determined the pig testicular $\mathrm{Cu}$ toxicity and found a complex relationship between oxidative stress, autophagy, and apoptosis in $\mathrm{Cu}$-exposed testes. The $\mathrm{Cu}$ exposure induces testicular oxidative stress and further damages testis by promoting apoptosis and autophagy, and apoptosis decreases testicular antioxidant capacity through mitochondrial pathway. These findings provide a new perspective into the mechanism toxicity by $\mathrm{Cu}$ in testis.

Availability of data and materials The datasets used and/or analyzed during the current study are available from the corresponding author on reasonable request.

Author contribution Y.L.L. and H.M.C. made equal contributions in conducting experiments. Z.X.T. and Y.L. provided the research idea. H.M.C., J.Z.L., K.L.C., N.Q., Q.W.Z., B.X.L., and J.N.Y. contributed reagents, materials, and analysis tools; Y.L.L. and M.T.J. wrote the manuscript. All the authors participated in manuscript writing and reviewing.

Funding This project was supported by the Guangdong Natural Science Foundation (2021A151501047). 


\section{Declarations}

Ethics approval All animal experiments were reviewed and approved by the Animal Ethics Care Committee of the South China Agriculture University.

Consent to participate All authors informed consent to participate in this study.

Consent for publication All authors agree to publish the article.

Conflict of interest The authors declare no competing interests.

\section{References}

Aitken RJ, Roman SD (2008) Antioxidant systems and oxidative stress in the testes. Oxidative Med Cell Longev 1(1):15-24. https://doi.org/ 10.4161/oxim.1.1.6843

Chen H, Sun J, He Y, Zou Q, Wu Q, Tang Y (2015) Expression and localization of testis developmental related gene 1 (TDRG1) in human spermatozoa. Tohoku J Exp Med 235(2):103-109. https://doi. org/10.1620/tjem.235.103

Chen H, Kang Z, Qiao N, Liu G, Huang K, Wang X, Pang C, Zeng Q, Tang Z, Li Y (2020) Chronic copper exposure induces hypospermatogenesis in mice by increasing apoptosis without affecting testosterone secretion. Bio Trace Element Res 195(2):472480. https://doi.org/10.1007/s12011-019-01852-x

Correia S, Cardoso HJ, Cavaco JE, Socorro S (2015) Oestrogens as apoptosis regulators in mammalian testis: angels or devils? Expert Rev Mol Med 17:e2. https://doi.org/10.1017/erm.2014.25

Eheliyagoda D, Wei F, Shan G, Albalghiti E, Zeng X, Li J (2019) Examining the temporal demand and sustainability of copper in China. Environ Sci Technol 53(23):13812-13821. https://doi.org/ 10.1021/acs.est.9b03875

Elmore S (2007) Apoptosis: a review of programmed cell death. Toxicol Pathol 35(4):495-516. https://doi.org/10.1080/ 01926230701320337

Estaquier J, Vallette F, Vayssiere JL, Mignotte B (2012) The mitochondrial pathways of apoptosis. Adv Exp Med Biol 942:157-183. https://doi.org/10.1007/978-94-007-2869-1_7

Filomeni G, De Zio D, Cecconi F (2015) Oxidative stress and autophagy: the clash between damage and metabolic needs. Cell Death Differ 22(3):377-388. https://doi.org/10.1038/cdd.2014.150

Ghaffari R, Di Bona KR, Riley CL, Richburg JH (2019) Copper transporter 1 (CTR1) expression by mouse testicular germ cells, but not Sertoli cells, is essential for functional spermatogenesis. PLoS One 14(4):e0215522. https://doi.org/10.1371/journal.pone.0215522

Glick D, Barth S, Macleod KF (2010) Autophagy: cellular and molecular mechanisms. J Pathol 221(1):3-12. https://doi.org/10.1002/path. 2697

Grande G, Vincenzoni F, Mancini F, Barrachina F, Giampietro A, Castagnola M, Urbani A, Oliva R, Milardi D, Pontecorvi A (2019) Quantitative analysis of the seminal plasma proteome in secondary hypogonadism. J Clin Med 8(12):2128. https://doi.org/10.3390/ jem8122128

Guo H, Li K, Wang W, Wang C, Shen Y (2017) Effects of copper on hemocyte apoptosis, ROS production, and gene expression in white shrimp Litopenaeus vannamei. Bio Trace Element Res 179(2):318 326. https://doi.org/10.1007/s12011-017-0974-6

He Y, Yang X, Xia J, Zhao L, Yang Y (2016) Consumption of meat and dairy products in China: a review. Proc Nutr Soc 75(3):385-391. https://doi.org/10.1017/S0029665116000641
Herman S, Lipiński P, Ogórek M, Starzyński R, Grzmil P, Bednarz A, Lenartowicz M (2020) Molecular regulation of copper homeostasis in the male gonad during the process of spermatogenesis. Int $\mathrm{J}$ Mol Sci 21(23):9053. https://doi.org/10.3390/ijms21239053

Hernandez A (2018) Thyroid hormone role and economy in the developing testis. Vitam Horm 106:473-500. https://doi.org/10.1016/bs.vh. 2017.06.005

Indo HP, Davidson M, Yen HC, Suenaga S, Tomita K, Nishii T, Higuchi M, Koga Y, Ozawa T, Majima HJ (2007) Evidence of ROS generation by mitochondria in cells with impaired electron transport chain and mitochondrial DNA damage. Mitochondrion 7(1-2):106-118. https://doi.org/10.1016/j.mito.2006.11.026

Jensen J, Larsen MM, Bak J (2016) National monitoring study in Denmark finds increased and critical levels of copper and zinc in arable soils fertilized with pig slurry. Environ Pollut 214:334-340. https://doi.org/10.1016/j.envpol.2016.03.034

Kang C, Punjani N, Lee RK, Li PS, Goldstein M (2021) Effect of varicoceles on spermatogenesis. Semin Cell Dev Biol S10849521(21)00078-1. Advance online publication. https://doi.org/10. 1016/j.semcdb.2021.04.005

Kerr JF, Wyllie AH, Currie AR (1972) Apoptosis: a basic biological phenomenon with wide-ranging implications in tissue kinetics. British J Can 26(4):239-257. https://doi.org/10.1038/bjc.1972.33

Kheirandish R, Askari N, Babaei H (2014) Zinc therapy improves deleterious effects of chronic copper administration on mice testes: histopathological evaluation. Andrologia 46(2):80-85. https://doi.org/ 10.1111/and.12047

Kim H, Wu X, Lee J (2013) SLC31 (CTR) family of copper transporters in health and disease. Mol Asp Med 34(2-3):561-570. https://doi. org/10.1016/j.mam.2012.07.011

Kreuz S, Fischle W (2016) Oxidative stress signaling to chromatin in health and disease. Epigenomics 8(6):843-862. https://doi.org/10. 2217/epi-2016-0002

Lee J, Prohaska JR, Thiele DJ (2001) Essential role for mammalian copper transporter Ctr1 in copper homeostasis and embryonic development. Proc Natl Acad Sci U S A 98(12):6842-6847. https://doi.org/ 10.1073/pnas. 111058698

Levine B, Kroemer G (2019) Biological functions of autophagy genes: a disease perspective. Cell 176(1-2):11-42. https://doi.org/10.1016/j. cell.2018.09.048

Li JL, Gao R, Li S, Wang JT, Tang ZX, Xu SW (2010) Testicular toxicity induced by dietary cadmium in cocks and ameliorative effect by selenium. Biometals : an international journal on the role of metal ions in biology, biochemistry, and medicine 23(4):695-705. https:// doi.org/10.1007/s10534-010-9334-0

Li X, Zhang J, Gong Y, Liu Q, Yang S, Ma J, Zhao L, Hou H (2020) Status of copper accumulation in agricultural soils across China (1985-2016). Chemosphere 244:125516. https://doi.org/10.1016/j. chemosphere.2019.125516

Li Q, Liao J, Lei C, Shi J, Zhang H, Han Q, Guo J, Hu L, Li Y, Pan J, Tang Z (2021) Metabolomics analysis reveals the effect of copper on autophagy in myocardia of pigs. Ecotoxicol Environ Saf 213: 112040. https://doi.org/10.1016/j.ecoenv.2021.112040

Liao J, Yang F, Chen H, Yu W, Han Q, Li Y, Hu L, Guo J, Pan J, Liang Z, Tang Z (2019) Effects of copper on oxidative stress and autophagy in hypothalamus of broilers. Ecotoxicol Environ Saf 185:109710. https://doi.org/10.1016/j.ecoenv.2019.109710

Lin S, Qiao N, Chen H, Tang Z, Han Q, Mehmood K, Fazlani SA, Hameed S, Li Y, Zhang H (2020) Integration of transcriptomic and metabolomic data reveals metabolic pathway alteration in mouse spermatogonia with the effect of copper exposure. Chemosphere 256:126974. https://doi.org/10.1016/j.chemosphere. 2020.126974

Liu Y, Espinosa CD, Abelilla JJ, Casas GA, Lagos LV, Lee SA, Kwon WB, Mathai JK, Navarro D, Jaworski NW, Stein HH (2018) Non- 
antibiotic feed additives in diets for pigs: a review. Animal nutrition 4(2):113-125. https://doi.org/10.1016/j.aninu.2018.01.007

Liu B, Zeng Q, Chen H, Liao J, Bai Y, Han Q, Qiao N, Wang S, Mehmood K, Hussain R, Ahmed BZ, Tang Z, Zhang H, Li Y (2021a) The hepatotoxicity of altrazine exposure in mice involves the intestinal microbiota. Chemosphere 272:129572. https://doi.org/ 10.1016/j.chemosphere.2021.129572

Liu B, Li Y, Mehmood K, Nabi F, Ahmed S, Tauseef-ur-Rehman FM, Ashraf M, Tang ZX, Zhang H (2021b) Role of oxidative stress and antioxidants in thiram-induced tibial dyschondroplasia. Pak Vet J 41(1):1-6. https://doi.org/10.29261/pakvetj/2020.094

Mirzayans R, Murray D (2020) Do TUNEL and other apoptosis assays detect cell death in preclinical studies? Int J Mol Sci 21(23):9090. https://doi.org/10.3390/ijms21239090

Modanloo M, Shokrzadeh M (2019) Analyzing mitochondrial dysfunction, oxidative stress, and apoptosis: potential role of L-carnitine. Iranian journal of kidney diseases 13(2):74-86

Ogórek M, Lenartowicz M, Starzyński R, Jończy A, Staroń R, Doniec A, Krzeptowski W, Bednarz A, Pierzchała O, Lipiński P, Rajfur Z, Baster Z, Gibas-Tybur P, Grzmil P (2017) Atp7a and Atp7b regulate copper homeostasis in developing male germ cells in mice. Metallomics: integrated biometal science 9(9):1288-1303. https:// doi.org/10.1039/c7mt00134g

Oskam JP (1989) Bloedafname bij het varken Blood collection in pigs. Tijdschr Diergeneeskd 114(7):376-380

Petris MJ, Voskoboinik I, Cater M, Smith K, Kim BE, Llanos RM, Strausak D, Camakaris J, Mercer JF (2002) Copper-regulated trafficking of the Menkes disease copper ATPase is associated with formation of a phosphorylated catalytic intermediate. J Biol Chem 277(48):46736-46742. https://doi.org/10.1074/jbc.M208864200

Sánchez-Martín P, Saito T, Komatsu M (2019) p62/SQSTM1: 'Jack of all trades' in health and cancer. FEBS J 286(1):8-23. https://doi.org/10. $1111 /$ febs. 14712

Satyavarapu EM, Das R, Mandal C, Mukhopadhyay A, Mandal C (2018) Autophagy-independent induction of LC3B through oxidative stress reveals its non-canonical role in anoikis of ovarian cancer cells. Cell Death Dis 9(10):934. https://doi.org/10.1038/s41419-018-0989-8

Savitskiy VP, Shman TV, Potapnev MP (2003) Comparative measurement of spontaneous apoptosis in pediatric acute leukemia by different techniques. Cytometry B Clin Cytom 56(1):16-22. https:// doi.org/10.1002/cyto.b.10056

Schulze M, Beyer S, Beyer F, Bortfeldt R, Riesenbeck A, Leiding C, Jung M, Kleve-Feld M (2020) Relationship between pubertal testicular ultrasonographic evaluation and future reproductive performance potential in Piétrain boars. Theriogenology 158:58-65. https://doi. org/10.1016/j.theriogenology.2020.09.003

Shao Y, Zhao H, Wang Y, Liu J, Zong H, Xing M (2019) Coppermediated mitochondrial fission/fusion is associated with intrinsic apoptosis and autophagy in the testis tissues of chicken. Bio Trace Element Res 188(2):468-477. https://doi.org/10.1007/s12011-0181427-6

Shi B, Ma M, Zheng Y, Pan Y, Lin X (2019) mTOR and Beclin1: two key autophagy-related molecules and their roles in myocardial ischemia/reperfusion injury. J Cell Physiol 234(8):12562-12568. https://doi.org/10.1002/jcp.28125

Sierens JE, Sneddon SF, Collins F, Millar MR, Saunders PT (2005) Estrogens in testis biology. Ann N Y Acad Sci 1061:65-76. https://doi.org/10.1196/annals.1336.008

Sinha K, Das J, Pal PB, Sil PC (2013) Oxidative stress: the mitochondriadependent and mitochondria-independent pathways of apoptosis. Arch Toxicol 87(7):1157-1180. https://doi.org/10.1007/s00204013-1034-4

Sun MH, Li XH, Xu Y, Xu Y, Sun SC (2020) Exposure to PBDE47 affects mouse oocyte quality via mitochondria dysfunctioninduced oxidative stress and apoptosis. Ecotoxicol Environ Saf 198:110662. https://doi.org/10.1016/j.ecoenv.2020.110662
Tapiero H, Townsend DM, Tew KD (2003) Trace elements in human physiology and pathology. Copper. Biomedicine \& pharmacotherapy $=$ Biomedecine \& pharmacotherapie 57(9):386-398. https://doi. org/10.1016/s0753-3322(03)00012-x

Tummers B, Green DR (2017) Caspase-8: regulating life and death. Immunol Rev 277(1):76-89. https://doi.org/10.1111/imr.12541

Van Erp AC, Hoeksma D, Rebolledo RA, Ottens PJ, Jochmans I, Monbaliu D, Pirenne J, Leuvenink H, Decuypere JP (2017) The crosstalk between ROS and autophagy in the field of transplantation medicine. Oxidative Med Cell Longev 2017:7120962-7120913. https://doi.org/10.1155/2017/7120962

Vázquez-Blanco R, Arias-Estévez M, Bååth E, Fernández-Calviño D (2020) Comparison of $\mathrm{Cu}$ salts and commercial $\mathrm{Cu}$ based fungicides on toxicity towards microorganisms in soil. Environmental pollution (Barking, Essex : 1987) 257:113585. https://doi.org/10.1016/j. envpol.2019.113585

Villagómez-Estrada S, Pérez JF, Darwich L, Vidal A, van Kuijk S, MeloDurán D, Solà-Oriol D (2020) Effects of copper and zinc sources and inclusion levels of copper on weanling pig performance and intestinal microbiota. J Anim Sci 98(5):skaa117. https://doi.org/10. 1093/jas/skaa117

Wan F, Zhong G, Ning Z, Liao J, Yu W, Wang C, Han Q, Li Y, Pan J, Tang Z, Huang R, Hu L (2020) Long-term exposure to copper induces autophagy and apoptosis through oxidative stress in rat kidneys. Ecotoxicol Environ Saf 190:110158. https://doi.org/10. 1016/j.ecoenv.2019.110158

Wang Y, Li A, Mehmood K, Hussain R, Abbas RZ, Javed MT, Chang YF, Hu L, Pan J, Li Y, Shi L, Tang Z, Zhang H (2021) Long-term exposure to the fluoride blocks the development of chondrocytes in the ducks: the molecular mechanism of fluoride regulating autophagy and apoptosis. Ecotoxicol Environ Saf 217:112225. https://doi. org/10.1016/j.ecoenv.2021.112225

Wells R, Kenny AL, Duckett R, Wreford NG, Johnston SD, D'Occhio MJ (2013) Elucidation of the role of LH and FSH during neonatal testicular development and growth in the pig. Anim Reprod Sci 137(12):74-81. https://doi.org/10.1016/j.anireprosci.2012.11.005

Yang W, Zhao C, Zhang C, Yang L (2016) High dietary copper increases catecholamine concentrations in the hypothalami and midbrains of growing pigs. Bio Trace Element Res 170(1):115-118. https://doi. org/10.1007/s12011-015-0460-y

Yang F, Cao H, Su R, Guo J, Li C, Pan J, Tang Z (2017a) Liver mitochondrial dysfunction and electron transport chain defect induced by high dietary copper in broilers. Poult Sci 96(9):3298-3304. https:// doi.org/10.3382/ps/pex137

Yang J, Hu S, Rao M, Hu L, Lei H, Wu Y, Wang Y, Ke D, Xia W, Zhu $\mathrm{CH}$ (2017b) Copper nanoparticle-induced ovarian injury, follicular atresia, apoptosis, and gene expression alterations in female rats. Int J Nanomedicine 12:5959-5971. https://doi.org/10.2147/IJN. S139215

Yang B, Chen Y, Shi J (2019a) Reactive oxygen species (ROS)-based nanomedicine. Chem Rev 119(8):4881-4985. https://doi.org/10. 1021/acs.chemrev.8b00626

Yang F, Pei R, Zhang Z, Liao J, Yu W, Qiao N, Han Q, Li Y, Hu L, Guo J, Pan J, Tang Z (2019b) Copper induces oxidative stress and apoptosis through mitochondria-mediated pathway in chicken hepatocytes. Toxicology in Vitro: An International Journal Published in Association with BIBRA 54:310-316. https://doi.org/10.1016/j.tiv. 2018.10.017

Zebral YD, Anni I, Junior A, Corcini CD, da Silva JC, Caldas JS, Acosta IB, Afonso SB, Bianchini A (2019) Life-time exposure to waterborne copper IV: sperm quality parameters are negatively affected in the killifish Poecilia vivipara. Chemosphere 236:124332. https://doi. org/10.1016/j.chemosphere.2019.07.063

Zhang ZW, Zhi-GangTan QN, Kang ZL, Chen ZL, Hu LM, Yang ZM, Li Y (2016) Copper-induced spermatozoa head malformation is related 
to oxidative damage to testes in CD-1 mice. Bio Trace Element Res 173(2):427-432. https://doi.org/10.1007/s12011-016-0675-6

Zhang H, Wang Y, Mehmood K, Chang YF, Tang Z, Li Y (2020) Treatment of tibial dyschondroplasia with traditional Chinese medicines: "lesson and future directions". Poult Sci 99(12):6422-6433. https://doi.org/10.1016/j.psj.2020.08.055

Zhao GX, Pan H, Ouyang DY, He XH (2015) The critical molecular interconnections in regulating apoptosis and autophagy. Ann Med 47(4):305-315. https://doi.org/10.3109/07853890.2015.1040831

Zhao D, Zhang X, Li X, Ru S, Wang Y, Yin J, Liu D (2019) Oxidative damage induced by copper in testis of the red swamp crayfish
Procambarus clarkii and its underlying mechanisms. Aquat Toxicol 207:120-131. https://doi.org/10.1016/j.aquatox.2018.12. 006

Zorov DB, Juhaszova M, Sollott SJ (2014) Mitochondrial reactive oxygen species (ROS) and ROS-induced ROS release. Physiol Rev 94(3):909-950. https://doi.org/10.1152/physrev.00026.2013

Publisher's note Springer Nature remains neutral with regard to jurisdictional claims in published maps and institutional affiliations. 